\title{
Differential public support for waste management policy: The case of Hong Kong
}

\begin{abstract}
Gaining public support for environmental policy can promote pro-environmental behaviors and facilitate policy implementation. A telephone survey was conducted in Hong Kong to solicit 504 respondents' level of support for different waste management policies and the role of key socio-demographic variables on the level of support for these policies. Data was examined by using multivariate analysis of variance (MANOVA). Findings revealed that significant variance exists within gender, age groups, and education on the level of policy support for different measures, while household size and political inclination exhibited less association with support for the policies. Respondents also indicated a varying level of support across policy tools, with policies of developing recycling industry and extending Producer Responsibility Scheme received more support, but municipal solid waste charging scheme and publicity and education measure were less welcomed among respondents. Our analysis infers that current waste management framework should be driven toward a more coherent mode in order to secure greater public support and maximize policy effectiveness. Policy implications could be applied to waste management framework development in cities which share similar background with Hong Kong.
\end{abstract}

Keywords: policy support; public acceptance; recycling; waste charging; social groups

\section{Introduction}

Public support is a key to successful implementation of waste management policy and policy goal achievement (Wan et al., 2017; Wan et al., 2015). It is particularly significant for environmental policies which emphasize active public participation such as recycling and recovery. Most previous research examined public support for waste management strategies by using single measurement (e.g., Afroz and Masud, 2011; Brown and Johnstone, 2014; Dietz et al., 1998; Elliott et al., 1995; Gelissen, 2007; Saphores et al., 2006). Though there have been a considerable number of studies examining the relationship between sociodemographic factors and level of policy support, little research explores the level of support for different waste management policy tools and the demographic differences across these policies in one study. Similarly, previous studies also confined to measurement deficiency (e.g., single measurement) that the results only provide us with limited understanding on the issue. Given the above background, this research has the aim to investigate the level of policy support and socio-demographic effect on the public support for various waste management options with reference to Hong Kong. Empirical evidence on the level of public support across policies and socio-demographic factors that account for the variations could inform the formulation of effective waste management strategies. It assists policy-makers to work out targeted measures that are responsive to public aspirations, thereby promotes public participation and facilitates policy implementation. The densely populated research context with scarce land resources available also gives a unique insight into countries which share similar background.

The study will first brief the study area and research background. Section 2 presents a review of the literature on policy support. Methodological details are given in section 3. Statistical results are reported in section 4. Section 5 is an extensive discussion of the results. Section 5.1 offers explanations for differential policy support across policies in relation to the 
phenomenon of uncoordinated waste management framework. Section 5.2 begins by comparing socio-demographic effect on the level of policy support with findings from previous studies; and put forward exposition of each finding by drawing reference to these studies. In section 5.3, a new framework toward a coherent management and policy relevance based on results are proposed. We also provide suggestions on recruiting public support targeted at people with different socio-demographic backgrounds in section 5.4. The paper will end with a note on the issue of framework applicability to other cities.

\section{Study area and research background}

Hong Kong is selected as our study area. It is a densely populated city with over 7.3 million population living in a terrestrial area of 1,105 square kilometers (Information Services Department, 2015). A large population, rapid economic growth, and consumptive culture have accelerated the amount of waste, making waste management in the city a challenging problem than ever before. According to the Environmental Protection Department (2017b), the quantity of disposal municipal solid waste (MSW) had increased by $11.5 \%$ from 9,114 tonnes in 2010 to 10,159 tonnes in 2015. Every Hong Kong citizen generated $1.39 \mathrm{~kg}$ of disposal MSW per day in 2015. The city has the highest daily per capita MSW rate compared to neighboring cities, about 1.36 times and 1.77 times higher than Taipei city and Tokyo, respectively (Environment Bureau, 2013).

Over the past decades, the Hong Kong government has relied heavily on landfilling as its core waste management strategy. Approximately $65 \%$ of MSW is taken to landfills for disposal, with the rest being recycled (Environmental Protection Department, 2017b). Waste minimization and prevention policies by contrast have never emerged as a preferred solution to waste problems. Development of policy in relation to waste prevention is fragmented, not well-formed, and ineffective. For example, a territory-wide source separation program introduced in 2005 was only made as a voluntary basis. While under the program, 3-colored separation bins were made available to over $80 \%$ of population for encouraging recycling practices, recycling rate of MSW between 2012 and 2015 remained at a low level of around $35 \%$ to $39 \%$ (Environmental Protection Department, 2017b). Regarding the producer responsibility scheme (PRS), only plastic shopping bag levy was fully introduced in 2015 since the enactment of Product Eco-responsibility Ordinance in 2008. Regulations for other types of product including vehicle tyres recycling have not yet been implemented.

Owning to the fact that the existing three landfills in Hong Kong are expected to reach full capacity by the end of this decade, in addition to space scarcity and escalating public opposition, landfilling is no longer a panacea for the impending municipal solid waste crisis. The government has recognized the urgency of shifting its waste management to a more sustainable direction and hence promulgated various initiatives in the latest blueprint for resources management (Environment Bureau, 2013). Policies promoting waste prevention and reduction to the higher levels of the waste hierarchy have been rolled out to advance the waste management. For instance, along with enhanced financial support for the development of recycling industry, the government introduced the legislative proposal of producer responsibility scheme for waste electrical and electronic equipment (WEEE) and glass beverage containers into the legislature. Under the new direction of waste management, the public are required to make behavioral changes in response to meet the target of reducing 40\% per capita MSW generation (Environment Bureau, 2013). Widespread public attention and support would be vital if waste avoidance and sustainable oriented waste management framework are to succeed (Xiao et al., 2017). It is this case calls for an in-depth examination

Page 2 of 27 
of policy support for different instruments, and optimal policy arrangements that could provide timely insight into gaining broader public support for the framework.

\section{Policy support and waste management policy}

Environmental instruments and regulations are set up for the purpose of mitigating deteriorating environmental problems and protecting the environment. Individuals showing policy support for environmental measures can be regarded as an indirect pro-environmental behavior (Kollmuss and Agyeman, 2002). It is a non-activist environmental significant behavior because people affect the environment indirectly through the means of exerting influence on environmental policies (Stern, 2000). The public may support or accept policies by making material sacrifice to achieve the goal of environmental protection, for example, individuals pay higher taxes or endorse increased spending on environmental issues; further, individuals may express support by way of voluntarily complying with policies or changing behaviors in private sphere in accordance with promulgated environmental guidelines and instruments (Stern et al., 1999).

Therefore, gaining policy support is an essential condition to the success of waste management because it enhances political feasibility for policy initiation and facilitates implementation of effective policy (Brown and Johnstone, 2014; Convery et al., 2007; Stern, 2000; Wan et al., 2015). New environmental policies would be easier to initiate if the authority is equipped with adequate public support (Rauwald and Moore, 2002). It is particularly significant for environmental policies with emphasis on waste separation and recycling programs which active public participation is required. Stern et al. (1999) pointed out that policy support is a barometer that can signal both authorities and industry about citizens' concerns of the environmental issues. Echoed with the argument, the present study emphasized that policy support can serve as an analytical tool of which by examining the level of public support for different policy instruments helps identify defects of existing waste management framework; subsequently, policy-makers can recommend or fine-tune programs that would gain greater public support (Brown and Johnstone, 2014; Ladd, 1990).

Socio-demographic characteristics are frequently used by prior studies as explanatory variables of environmental policy support or willingness to pay for environmental protection. Age is a consistent predictor of policy support which younger generation in general is more prone to support for environmental policy than their older counterparts (Afroz and Masud, 2011; Brown and Johnstone, 2014; Dietz et al., 1998; Gelissen, 2007; Jones and Dunlap, 1992). Regarding gender effect, females were found to be more concerned about environmental problems (Blocker and Eckberg, 1989; Schultz et al., 1995; Triguero et al., 2016) and more willing to pay for environmental protection than men (Bartelings and Sterner, 1999; Stern et al., 1993). Education level is a less robust determinant. Some studies proved that educated people are prone to support increased environmental spending and committed as environmentalists (Barr et al., 2005; Brown and Johnstone, 2014; Dietz et al., 1998; Gelissen, 2007; Jones and Dunlap, 1992; Triguero et al., 2016), however a negative effect was found by Samdahl and Robertson (1989). Similarly, yet many studies proved that higher income results in greater support for environmental policy or involvement in proenvironmental behaviors (e.g., Elliott et al., 1995; Gelissen, 2007; Milovantseva, 2016; Oskamp, 1995), but not Challcharoenwattana and Pharino (2016), Samdahl and Robertson (1989), Scott (1999) and Zeng et al. (2016). The mixed results may due to heterogeneous contextual background such as social, cultural, economic, political, and regional variation exist in these studies.

Page 3 of 27 
Previous studies used environmental spending or willingness to pay or a single policy item as a proxy for measuring the level of support for environmental policy (e.g., Dietz et al., 1998; Gelissen, 2007). The reliance on proxy or single measurement may lead to inaccurate interpretation of public opinion on waste management framework, especially public's reflection on specific policy. Recently, Triguero et al. (2016) improved the measurement by adding the dimension of measuring policy support; the authors divided waste management solutions in terms of government responsibility, consumer responsibility, and producer responsibility, and evaluated respondents' preference for these options. However, it remains unclear the extent to which people incline toward a particular kind of waste management instrument. As suggested by Ladd (1990), data of public support for every policy tool is essential to recommendation of programs which can gain public support; and thereby it should have a place in future studies. In light of this, a further step was taken to investigate the level of policy support by measuring different kinds of policy instruments in this study. With reference to the socio-demographic factors, findings are expected to give an insight into the optimal combination of different waste management policies that would generate a broader public support and achieve greater effectiveness of waste management framework.

The current literature suffers from defective measurement for policy support and a lack of studies investigating socio-demographic effect in relation to a broad range of policy categories. This paper attempts to fill the gaps by analyzing level of policy support of each waste management policy and social structures that govern people's support for these policies. The study would enable intelligences to accurately understand socio-demographic effects on policy support and grasp the overall level of support for different policy measures, with specific reference given to a densely populated city with limited land resources available and high volumes of waste generation. Explanations accounting for the variations will be examined and suggestions integrating the findings into the development of coherent waste management governance will be discussed. Results help formulate waste management policies targeted at specific groups and adjust measures according to the level of policy support, and thereby enabling authorities to gain public support and implement waste management policies with greater success.

\section{Methodology}

\subsection{Questionnaire and variables description}

With the aim of obtaining a higher response rate, telephone survey was chosen to collect data for this research. It enables interviewers to establish rapport and trust with respondents. Interpersonal communication offers both interviewers and respondents opportunities to clarify questions and answers, respectively. Subsequently, the survey tends to have a higher response rate that non-response error could be reduced (Fowler, 2014; Hine et al., 2016). It is

also a cost-effective option compared to other methods such as face-to-face interview and mail survey.

The primary focus of this study examines level of public support for different waste management policies, and how it varies through the population with reference to key sociodemographic variables. A survey questionnaire which consists of two sections was developed for data collection. The first section solicits respondents' level of support for different policy measures. It contains eight policy items which were formed by drawing reference to current waste management policies (PS1, PS3, PS5-PS7) and proposed initiatives (PS2, PS4, PS8) 
suggested by authorities in Hong Kong (Table 2) (Environment Bureau, 2013). Among the policy items, Recycling Fund for Industry (PS6) and EcoPark (PS7) are specific to Hong Kong context. The former is a HK $\$ 1$ billion funding set up for local enterprises to upgrade and expand their waste recycling operations and for non-profit organization to undertake recycling related projects. EcoPark is constructed by the Hong Kong government to provide rentable long-term land at affordable costs for local recycling industry. Since the main concern of this study is with policies that could promote pro-environmental behaviors, endof-pipe measures such as landfilling will be excluded for assessment. Respondents were required to rate each policy item by using a seven-point Likert scale from 1 (strongly disagree) to 7 (strongly agree). A higher score denotes respondents' more supportive attitude toward the policy measures.

The second section gathers respondents' socio-demographic background. Information about gender, age, education level, income level, household size, and political inclination will be asked. Categorizations of each socio-demographic variable are presented in Table 1. Variables (i.e., age, income, education, household size) are divided into subgroups by referring to the approach adopted by Census and Statistics Department, Hong Kong. Political inclination refers an individuals' political stance of public affairs. As illustrated, there are roughly four political alignments and they represent different positions on the political spectrum in Hong Kong. Generally, pro-democracy and pro-localism camps are more democratic and liberal whereas stance of pro-establishment camp is more conservative and pro-China; and pro-centrists position themselves in between these alignments. All information is necessary for the purpose of investigating the extent to which difference in level of support for policy tools would associate with respondents' socio-demographic background.

\subsection{Data collection and analysis}

The sample was collected from a random household telephone survey conducted from July to August 2016. The fieldwork was conducted at $6: 30 \mathrm{pm}$ to $10: 30 \mathrm{pm}$ every day. A set of telephone numbers were randomly selected using known prefixes assigned to telecommunication services provides under the Numbering Plan provided by the Office of the Communications Authority, Hong Kong. Cantonese-speaking Hong Kong residents (constitutes over $90 \%$ of the population (Census and Statistics Department, 2016)) aged 18 to 65 were targeted for an interview in accordance with the last birthday selection rule. The valid response rate was $76.1 \%$ and the survey received a total of 504 valid responses. Suggested by Ariola (2006, p.140, see also Ryan, 2013, pp.19-20), Slovin's formula (required samples $=$ total population $/\left(1+\right.$ total population $\mathrm{x}$ desired margin of error $\left.\left.^{2}\right)\right)$ was used to determine the minimum sample size if there is ignorance of the behavior of the population. Given a confidence level was set at $95 \%$ with Hong Kong total population size of around 7.3 million, the minimum sample size is 399.98. Thus, a valid sample of 504 is sufficient to warrant conclusions. The profile of respondents is presented in Table 1.

To ensure representativeness of the findings, the sample was statistically weighted before proceed to data analysis. It was weighted in accordance with figures obtained from the Census and Statistics Department regarding the age-gender distribution of year-end Hong Kong population in 2015 and the educational attainment (highest level attended) distribution collected in the 2011 Census. The purpose of this study is to determine the effect and variations of socio-demographic factors on the level of policy support and therefore a multivariate analysis of variance (MANOVA) was performed for data analysis. It allows the 
examination of effect of one or more independent variables on multiple continuous dependent variables. The follow-up analyses (post hoc test) also determine whether there are significant differences between groups of an independent variable on the level of support for each policy.

Table 1 Respondents' profiles

\begin{tabular}{|c|c|c|c|c|c|}
\hline Variables & $\begin{array}{c}\text { Frequency* } \\
(\%)\end{array}$ & \begin{tabular}{|c|}
$\begin{array}{c}\text { Frequency\# } \\
(\%)\end{array}$ \\
\end{tabular} & Variables & \begin{tabular}{|c|}
$\begin{array}{c}\text { Frequency* } \\
(\%)\end{array}$ \\
\end{tabular} & $\begin{array}{l}\text { Frequency\# } \\
(\%) \\
\end{array}$ \\
\hline Gender & & & Education & & \\
\hline Male & $43.70 \%$ & $46.60 \%$ & Primary or below & $7.30 \%$ & $13.50 \%$ \\
\hline Female & $56.30 \%$ & $53.40 \%$ & Lower secondary & $10.94 \%$ & $11.90 \%$ \\
\hline Age & & & Upper secondary & $32.19 \%$ & $41.65 \%$ \\
\hline $18-29$ & $21.96 \%$ & $27.94 \%$ & Bachelor's degree & $41.42 \%$ & $27.69 \%$ \\
\hline $30-39$ & $12.61 \%$ & $20.79 \%$ & Master's degree or above & $8.15 \%$ & $5.26 \%$ \\
\hline $40-49$ & $23.04 \%$ & $18.24 \%$ & Household size & & \\
\hline $50-59$ & $26.74 \%$ & $23.09 \%$ & 1-person & $5.04 \%$ & $4.19 \%$ \\
\hline $60-65$ & $15.65 \%$ & $9.93 \%$ & 2-person & $16.67 \%$ & $12.79 \%$ \\
\hline Income & & & 3-person & $25.00 \%$ & $26.98 \%$ \\
\hline Below HK\$5,000 & $27.02 \%$ & $26.84 \%$ & 4-person & $36.62 \%$ & $36.28 \%$ \\
\hline HK $\$ 5,000-9,999$ & $7.85 \%$ & $11.40 \%$ & $5+$ person & $16.67 \%$ & $19.77 \%$ \\
\hline HK\$10,000 - 19,999 & $24.71 \%$ & $29.45 \%$ & Political inclination & & \\
\hline HK\$20,000 - 29,999 & $17.55 \%$ & $18.05 \%$ & Pro-democracy camp & $22.72 \%$ & $19.38 \%$ \\
\hline HK $\$ 30,000-39,999$ & $7.39 \%$ & $6.41 \%$ & Pro-localism camp & $7.57 \%$ & $8.61 \%$ \\
\hline \multirow[t]{3}{*}{ HK $\$ 40,000$ or above } & $15.47 \%$ & $7.84 \%$ & Pro-centrist camp & $35.86 \%$ & $36.84 \%$ \\
\hline & & & Pro-establishment camp & $8.46 \%$ & $8.37 \%$ \\
\hline & & & $\begin{array}{l}\text { No political inclination / Political } \\
\text { neutral / Not belong to any camp }\end{array}$ & $25.39 \%$ & $26.79 \%$ \\
\hline
\end{tabular}

Remarks:

(1) *unweighted data; \#weighted data

(2) Lower secondary and upper secondary education in Hong Kong is equivalent to $7^{\text {th }}-9^{\text {th }}$ grade and $10^{\text {th }}-12^{\text {th }}$ grade of education in the United States, respectively.

\section{Findings}

\subsection{Public support for current waste management framework}

There is a modest degree of consensual support for waste management policies overall (Table 2). Around $55 \%$ to $65 \%$ of respondents indicated their choices as "strongly agree" and "agree" for every policy measure. Mean scores of all policy tools are above 5.0, with an overall average of 5.77. Policy measures have been ranked in order of the mean score.

Among eight policy measures, respondents rated investment in recycling and recovery infrastructure as the top of their list of policy support (mean score 5.92). Both Recycling Fund (PS6) and development of EcoPark (PS7) also occupied a relative high ranking (mean score 5.77). Adequate recycling facilities and well-developed recovery chain encourage recycling practices. The relatively high levels of support for these measures (i.e., PS6-PS8) imply that Hong Kong citizens eagerly call for the government to take up greater responsibility for fostering an enabling recycling environment. Meanwhile, the problem of excessive packaging and inappropriate treatments of end-of-life products are serious in Hong Kong. People have made a demand for extending Producer Responsibility Scheme (PS4; mean score 5.89) with a view to "polluter pays" principle which manufacturers should 
assume part of the environmental responsibility. Concerning the Construction Waste Disposal Charging Scheme (PS3), the public generally admitted to their responsibility of paying for construction waste generation and thus placed it on the third place of their supporting list (mean score 5.87).

The survey revealed that not all policy measures are equally well-received by the public. Municipal Solid Waste Charging Scheme (PS2) and Plastic Shopping Bag Levy (PS1) are least supported by respondents, with a mean score of 5.55 and 5.67 respectively. The two charging schemes aim at providing financial incentives to encourage people participating in recycling activities and thereby reduce waste volume (Dunne et al., 2008; Ferrara and Missios, 2005; Yang and Innes, 2007). In Hong Kong insufficient complementary measures such as provision of source separation facilities may contribute to the low score of support for the Municipal Solid Waste Charging Scheme. Regarding the Plastic Shopping Bag Levy, it is a disincentive that incurred financial costs to shoppers (Wan et al., 2015) and thereby erodes public support. Despite the fact that publicity work and education campaigns on waste reduction (PS5) help consolidate environmental consciousness among people and boost recycling rate, the measure is not overwhelmingly welcomed by Hong Kong respondents in comparison with other instruments, only takes up a middle ranking of the list. 
Table 2 Level of policy support by respondents (percent of valid respondents)

\begin{tabular}{|c|c|c|c|c|c|c|c|c|c|}
\hline Measurement of policy support ${ }^{\mathrm{a}}$ & $\begin{array}{l}\text { Strongly } \\
\text { disagree }\end{array}$ & Disagree & $\begin{array}{l}\text { Slightly } \\
\text { disagree }\end{array}$ & Neutral & $\begin{array}{c}\text { Slightly } \\
\text { agree }\end{array}$ & Agree & $\begin{array}{c}\text { Strongly } \\
\text { agree }\end{array}$ & Mean & $\operatorname{Rank}^{\mathrm{b}}$ \\
\hline PS1 (Plastic Shopping Bag Levy) & 2.3 & 1.1 & 4.8 & 13.1 & 19.0 & 20.1 & 39.6 & 5.64 & 6 \\
\hline PS2 (MSW Charging)^ & 1.5 & 2.3 & 3.8 & 11.7 & 25.4 & 23.6 & 31.6 & 5.55 & 7 \\
\hline PS3 (Construction Waste Charging) & 0.5 & 0.0 & 2.2 & 9.4 & 23.4 & 25.8 & 38.6 & 5.87 & 3 \\
\hline PS4 (Producer Responsibility Scheme) ${ }^{\wedge}$ & 0.3 & 1.2 & 1.7 & 6.8 & 24.8 & 26.0 & 39.2 & 5.89 & 2 \\
\hline PS5 (Publicity \& Education Campaign) $)^{\#}$ & 1.1 & 0.3 & 1.8 & 10.4 & 27.4 & 24.4 & 34.6 & 5.74 & 5 \\
\hline PS6 (Recycling Fund for Industry) & 1.2 & 0.7 & 2.7 & 8.5 & 25.7 & 25.2 & 36.1 & 5.77 & 4 \\
\hline PS7 (EcoPark) $)^{\#}$ & 1.3 & 1.2 & 3.1 & 7.4 & 24.4 & 25.7 & 36.9 & 5.77 & 4 \\
\hline PS8 (Recycling \& Recovery Infrastructure) ${ }^{\wedge}$ & 0.3 & 0.4 & 2.0 & 8.8 & 22.8 & 24.4 & 41.4 & 5.92 & 1 \\
\hline
\end{tabular}

${ }^{a}$ PS1 - I support the full implementation of Plastic Shopping Bag Levy.

PS2 - I support the Municipal Solid Waste Charging Scheme.

PS3 - I support the Construction Waste Disposal Charging Scheme.

PS4 - I support extending the Producer Responsibility Scheme to other recyclable materials (e.g., packing materials).

PS5 - I support earmarking funding to enhance publicity work and education campaigns on waste reduction.

PS6 - I support establishing the Recycling Fund to promote the development of local recycling industry.

PS7 - I support the development of an EcoPark for the local recycling industry.

PS8 - I support government's investment in recycling and recovery infrastructure.

${ }^{b}$ The mean score was used to rank the policy measures.

\# Current waste management policy

${ }^{\wedge}$ Suggested policy initiative 


\subsection{Discriminating policy supporters by socio-demographic characteristics}

Multivariate analysis of variance (MANOVA) was performed to analyze the dispersion of policy support with regard to respondents' major socio-demographic characteristics. Scheffe comparison was selected in the post hoc test. It enables researchers to determine whether there are significant differences among groups of an independent factor on the means of dependent variables (George and Mallery, 2016). Gender effect is associated with support for waste management policy (Pillai's trace $=0.046 ; p=0.008$ ). In general, females are more likely to support for every assessed waste management policy than males (Table 3). Four out of eight policy measures showed notable differences between males and females. Compared with men, women tend to more support for Plastic Shopping Bag Levy $(p=0.001)$ and earmarking additional resources for enhancing publicity work and education campaigns on waste reduction $(p=0.027)$. Female respondents also slightly differed from their male counterparts regarding the Municipal Solid Waste Charging Scheme (PS2, 5.68 versus 5.42) and the development of EcoPark for promoting local recycling industry (PS7, 5.82 versus 5.57 ).

Table 3 Level of policy support by respondent gender

\begin{tabular}{lcccc}
\hline Measurement of policy support & \multicolumn{3}{l}{ Gender (Pillai's trace $=0.046 ; p=0.008)$} \\
\cline { 2 - 4 } & Male & Female & $\begin{array}{r}F \text { Value } \\
\text { (df }=1)\end{array}$ & $p$ \\
\hline PS1 (Plastic Shopping Bag Levy) & 5.42 & 5.87 & 10.331 & 0.001 \\
PS2 (MSW Charging) & 5.42 & 5.68 & 4.015 & 0.046 \\
PS3 (Construction Waste Charging) & 5.75 & 5.95 & 3.806 & 0.052 \\
PS4 (Producer Responsibility Scheme) & 5.80 & 5.93 & 1.374 & 0.242 \\
PS5 (Publicity \& Education Campaign) & 5.57 & 5.82 & 4.920 & 0.027 \\
PS6 (Recycling Fund for Industry) & 5.67 & 5.84 & 2.121 & 0.146 \\
PS7 (EcoPark) & 5.57 & 5.82 & 4.182 & 0.041 \\
PS8 (Recycling \& Recovery Infrastructure) & 5.91 & 5.87 & 0.197 & 0.657 \\
\hline
\end{tabular}

A statistically significant association was found between age and level of policy support (Pillai's trace $=0.154 ; p=0.000$ ), with four policy measures showing remarkable differences across different age groups (Table 4). The 30-39 group expressed the highest level of support for the Municipal Solid Waste Charging Scheme (5.93) among age groups. It significantly differed from the age group 18-29 $(p=0.039)$ and the age group 50-59 $(p=0.038)$. Regarding charging scheme on Construction Waste Disposal, the 30-39 age group (6.19) showed more support than age group 18-29 $(p=0.018)$ and age group 60-65 $(p=0.013)$. The 18-29 generation (5.36) was less in favor of the development of Ecopark for local recycling industry compared with the 30-39 age group (5.93). Concerning investment in recycling and recovery infrastructure, the 18-29 age group differed significantly from the 30-39 $(p=0.001)$ and 40-49 age group $(p=0.003)$. Overall, the mature population, compared with the youngster group (aged 18-29), tended to agree with and support the waste management policies. 
Table 4 Level of policy support by respondent age

\begin{tabular}{|c|c|c|c|c|c|c|c|c|}
\hline \multirow[t]{2}{*}{ Measurement of policy support } & \multicolumn{8}{|c|}{ Age* (Pillai's trace $=0.154 ; p=0.000)$} \\
\hline & 1 & 2 & 3 & 4 & 5 & $\begin{array}{r}F \text { Value } \\
(\mathrm{df}=4)\end{array}$ & $p$ & $p$ in the Scheffe comparison \\
\hline PS1 (Plastic Shopping Bag Levy) & 5.50 & 6.03 & 5.62 & 5.56 & 5.65 & 1.956 & 0.100 & \\
\hline PS2 (MSW Charging) & 5.34 & 5.93 & 5.77 & 5.31 & 5.58 & 3.939 & 0.004 & $p(1,2)=0.039 ; p(2,4)=0.038$ \\
\hline PS3 (Construction Waste Charging) & 5.66 & 6.19 & 6.00 & 5.83 & 5.47 & 4.813 & 0.001 & $p(1,2)=0.018 ; p(2,5)=0.013$ \\
\hline PS4 (Producer Responsibility Scheme) & 5.69 & 6.00 & 5.90 & 5.87 & 6.00 & 1.176 & 0.321 & \\
\hline PS5 (Publicity \& Education Campaign) & 5.40 & 5.66 & 5.87 & 5.85 & 5.98 & 3.164 & 0.014 & \\
\hline PS6 (Recycling Fund for Industry) & 5.54 & 6.00 & 5.89 & 5.74 & 5.74 & 2.171 & 0.071 & \\
\hline PS7 (EcoPark) & 5.36 & 5.93 & 5.86 & 5.72 & 5.86 & 3.198 & 0.013 & $p(1,2)=0.045$ \\
\hline PS8 (Recycling \& Recovery Infrastructure) & 5.52 & 6.19 & 6.18 & 5.85 & 5.86 & 6.271 & 0.000 & $p(1,2)=0.001 ; p(1,3)=0.003$ \\
\hline
\end{tabular}


There is a significant effect of education on the level of policy support (Pillai's trace $=0.156 ; p$ $=0.000$ ) (Table 5). Post hoc analysis was performed to detect which education level creates the differences on various policy measures. It was found that respondents with lower education displayed a greater support for spending money on publicity work and education campaigns on waste reduction when compared to their upper secondary counterparts $(p=0.033)$ and Bachelor's degree group ( $p=0.007)$. In addition, respondents with Master's degree or above are more prone to the establishment of Recycling Fund and investment in recycling and recovery infrastructure compared to Bachelor's degree respondents ( $p=0.034$ and $p=0.018$ respectively).

Although there is a significant income effect (Pillai's trace $=0.140 ; p=0.027$ ) (Table 6), there is no significant pairwise differences among the income groups revealed in the post hoc analysis.

Household size only predicted the support for enhancing publicity work and education campaigns on waste reduction ( $p=0.007$ ). Households with 5 or more persons (mean score 5.27) tended to be less support for the policy, whereas the 3-person family showed a greater support for promotional policy (mean score 5.81) (Table 7).

Finally, effect of individual political inclination on level of policy support was considered. The statistical analysis revealed a significant multivariate main effect for political inclination (Pillai's trace $=0.127 ; p=0.010$ ) (Table 8). In follow-up tests, the means of two policy measures (PS1 and PS5) differed across political inclination. Pro-localism camp respondents demonstrated a lower level of support for Plastic Shopping Bag Levy compared to respondents with no political inclination $(p=0.022)$. A similar result was found for the policy of earmarking resources for publicity work and education campaigns on waste reduction, though the difference between prolocalism camp respondents and pro-establishment people are statistically weak $(p=0.044)$. 
Table 5 Level of policy support by respondent education

\begin{tabular}{|c|c|c|c|c|c|c|c|c|}
\hline \multirow[t]{2}{*}{ Measurement of policy support } & \multicolumn{8}{|c|}{ Education level $*($ Pillai's trace $=0.156 ; p=0.000)$} \\
\hline & 1 & 2 & 3 & 4 & 5 & $\begin{array}{l}F \text { Value } \\
(\mathrm{df}=4)\end{array}$ & $p$ & $p$ in the Scheffe comparison \\
\hline PS1 (Plastic Shopping Bag Levy) & 5.68 & 5.69 & 5.80 & 5.38 & 6.09 & 2.011 & 0.092 & \\
\hline PS2 (MSW Charging) & 5.37 & 5.71 & 5.55 & 5.57 & 5.96 & 0.930 & 0.446 & \\
\hline PS3 (Construction Waste Charging) & 5.64 & 6.13 & 5.85 & 5.80 & 6.30 & 2.413 & 0.048 & \\
\hline PS4 (Producer Responsibility Scheme) & 5.85 & 6.10 & 5.94 & 5.65 & 6.17 & 2.243 & 0.064 & \\
\hline PS5 (Publicity \& Education Campaign) & 6.24 & 5.75 & 5.65 & 5.51 & 5.74 & 3.766 & 0.005 & $p(1,3)=0.033 ; p(1,4)=0.007$ \\
\hline PS6 (Recycling Fund for Industry) & 5.83 & 5.96 & 5.82 & 5.47 & 6.35 & 3.735 & 0.005 & $p(4,5)=0.034$ \\
\hline PS7 (EcoPark) & 5.80 & 5.85 & 5.76 & 5.54 & 5.74 & 0.791 & 0.532 & \\
\hline PS8 (Recycling \& Recovery Infrastructure) & 5.95 & 5.98 & 5.87 & 5.72 & 6.61 & 3.162 & 0.014 & $p(4,5)=0.018$ \\
\hline
\end{tabular}

$* 1=$ Primary or below; 2 = Lower secondary; 3 = Upper secondary; 4 = Bachelor's degree; 5 = Master's degree or above

Table 6 Level of policy support by respondent income level

\begin{tabular}{|c|c|c|c|c|c|c|c|c|c|}
\hline \multirow[t]{2}{*}{ Measurement of policy support } & \multicolumn{9}{|c|}{ Income level* (Pillai's trace $=0.140 ; p=0.027$ ) } \\
\hline & 1 & 2 & 3 & 4 & 5 & 6 & $\begin{array}{l}F \text { Value } \\
(\mathrm{df}=5)\end{array}$ & $p$ & $p$ in the Scheffe comparison \\
\hline PS1 (Plastic Shopping Bag Levy) & 5.70 & 5.85 & 5.65 & 5.63 & 5.44 & 5.97 & 0.566 & 0.726 & \\
\hline PS2 (MSW Charging) & 5.52 & 5.40 & 5.56 & 5.59 & 6.00 & 5.85 & 1.015 & 0.408 & \\
\hline PS3 (Construction Waste Charging) & 5.73 & 6.00 & 5.95 & 5.76 & 5.74 & 6.21 & 1.499 & 0.189 & \\
\hline PS4 (Producer Responsibility Scheme) & 5.91 & 5.67 & 5.90 & 5.76 & 6.15 & 6.24 & 1.578 & 0.165 & \\
\hline PS5 (Publicity \& Education Campaign) & 5.73 & 5.96 & 5.63 & 5.54 & 6.04 & 5.82 & 1.298 & 0.264 & \\
\hline PS6 (Recycling Fund for Industry) & 5.69 & 5.77 & 5.72 & 5.92 & 5.89 & 6.12 & 1.015 & 0.408 & \\
\hline PS7 (EcoPark) & 5.58 & 5.73 & 5.70 & 5.79 & 5.81 & 6.18 & 1.176 & 0.320 & \\
\hline PS8 (Recycling \& Recovery Infrastructure) & 5.70 & 6.29 & 5.80 & 5.93 & 5.78 & 6.39 & 3.439 & 0.005 & \\
\hline
\end{tabular}

* $1<\mathrm{HK} \$ 5,000 ; 2$ = HK $\$ 5,000-9,999 ; 3=\mathrm{HK} \$ 10,000-19,999 ; 4$ = HK $\$ 20,000-29,999 ; 5=\mathrm{HK} \$ 30,000-39,999 ; 6 \geq \mathrm{HK} \$ 40,000$ 
Table 7 Level of policy support by respondent household size

\begin{tabular}{|c|c|c|c|c|c|c|c|c|}
\hline \multirow[t]{2}{*}{ Measurement of policy support } & \multicolumn{8}{|c|}{ Household Size* $($ Pillai's trace $=0.124 ; p=0.010)$} \\
\hline & 1 & 2 & 3 & 4 & 5 & $\begin{array}{l}F \text { Value } \\
(\mathrm{df}=4)\end{array}$ & $p$ & $p$ in the Scheffe comparison \\
\hline PS1 (Plastic Shopping Bag Levy) & 5.61 & 5.56 & 5.84 & 5.61 & 5.71 & 0.547 & 0.702 & \multirow{8}{*}{$p(3,5)=0.047$} \\
\hline PS2 (MSW Charging) & 5.50 & 5.58 & 5.53 & 5.81 & 5.32 & 2.045 & 0.087 & \\
\hline PS3 (Construction Waste Charging) & 5.50 & 5.73 & 5.94 & 5.98 & 5.72 & 1.633 & 0.165 & \\
\hline PS4 (Producer Responsibility Scheme) & 6.17 & 5.85 & 5.78 & 6.02 & 5.71 & 1.640 & 0.163 & \\
\hline PS5 (Publicity \& Education Campaign) & 6.00 & 5.87 & 5.81 & 5.76 & 5.27 & 3.564 & 0.007 & \\
\hline PS6 (Recycling Fund for Industry) & 5.78 & 5.60 & 5.77 & 5.88 & 5.67 & 0.726 & 0.574 & \\
\hline PS7 (EcoPark) & 5.72 & 5.69 & 5.74 & 5.76 & 5.61 & 0.185 & 0.946 & \\
\hline PS8 (Recycling \& Recovery Infrastructure) & 5.78 & 5.82 & 6.00 & 5.86 & 5.86 & 0.407 & 0.804 & \\
\hline
\end{tabular}

* 1 = 1-person; 2 = 2-person; $3=3$-person; 4 = 4-person; $5 \geq 5$-person

Table 8 Level of policy support by respondent political affiliation

\begin{tabular}{|c|c|c|c|c|c|c|c|c|}
\hline \multirow[t]{2}{*}{ Measurement of policy support } & \multicolumn{8}{|c|}{ Political Inclination* $($ Pillai's trace $=0.127 ; p=0.010)$} \\
\hline & 1 & 2 & 3 & 4 & 5 & $\begin{array}{c}F \text { Value } \\
(\mathrm{df}=4)\end{array}$ & $p$ & $p$ in the Scheffee comparison \\
\hline PS1 (Plastic Shopping Bag Levy) & 5.68 & 5.00 & 5.62 & 5.97 & 5.90 & 3.315 & 0.011 & $p(2,5)=0.022$ \\
\hline PS2 (MSW Charging) & 5.64 & 5.42 & 5.63 & 5.69 & 5.45 & 0.556 & 0.695 & \\
\hline PS3 (Construction Waste Charging) & 5.77 & 5.45 & 6.03 & 6.03 & 5.71 & 3.065 & 0.017 & \\
\hline PS4 (Producer Responsibility Scheme) & 5.99 & 5.37 & 5.92 & 6.00 & 5.83 & 2.355 & 0.053 & \\
\hline PS5 (Publicity \& Education Campaign) & 5.83 & 5.08 & 5.66 & 5.97 & 5.76 & 3.263 & 0.012 & $p(1,2)=0.044 ; p(2,4)=0.044$ \\
\hline PS6 (Recycling Fund for Industry) & 5.81 & 5.53 & 5.71 & 6.23 & 5.70 & 1.834 & 0.121 & \\
\hline PS7 (EcoPark) & 5.79 & 5.18 & 5.68 & 5.89 & 5.74 & 1.760 & 0.136 & \\
\hline PS8 (Recycling \& Recovery Infrastructure) & 5.91 & 5.66 & 5.95 & 6.00 & 5.80 & 0.731 & 0.571 & \\
\hline
\end{tabular}

$* 1$ = Inclined toward the pro-democracy camp; 2 = Inclined toward the pro-localism camp; 3 = Inclined toward the pro-centrist camp;

$4=$ Inclined toward the pro-establishment camp; $5=$ No political inclination / Politically neutral / Not belong to any camp 


\section{Discussion}

\subsection{Uncoordinated waste management framework}

This study revealed that respondents possess differential support for current waste management policies, in spite of the assessed policies belong to the same policy category (Table 2). For instance, Hong Kong people gave preference for policies related to the development of recycling industry (i.e., PS6-PS8) over promotional measure (PS5), though they are instruments based on government responsibility or belong to policy tools which aim at investing in the future development of the intellectual knowledge of the individual and industry development (Wan et al., 2015). Likewise, people welcomed the Construction Waste Disposal Charging Scheme but not for the charging scheme of municipal solid waste. The emerged trend of support for major waste management policies need to be explained in order to formulate policies with greater public support and achieve policy goals effectively.

The incompetent development of recycling chain in Hong Kong explained the high score of support for most policy measures of recycling industry development (PS6-PS8). With enhanced public education programs over the years and the introduction of Territory-wide Source Separation Program for domestic waste program in 2005, increasing number of Hong Kong people have developed a recycling habit (Ko and Poon, 2009). Nonetheless, structural defects of recycling chain hinder Hong Kong people in their efforts to do recycling. In Hong Kong, there is around one litter bin for every 187 people while the ratio of rubbish bin to recycling bin is 10:1 (Kao, 2014; Woodring, 2015). Most waste separation bins are limited to three types of recovered waste, i.e., waste paper, plastic bottles, and aluminum cans; scope of recyclables recovered has yet been widely extended to other types of recyclables and corresponding recycling facilities are hardly found within communities, resulting in most reusable resources end up at landfills. For example, $98 \%$ of generated food waste (around 1.33 million tonnes) was disposed of at landfills, accounting for 38\% of total volume of disposed MSW in 2013 (Audit Commission, 2015).

The problem is further complicated by the dysfunction of recycling system in Hong Kong. Shortage of land resources increases operation cost of recycling traders. Besides, over $90 \%$ of collected recyclables in Hong Kong could only be exported to other regions or countries for further processing or directly dumped into landfills because there is a lack of well-established local market for the recycled materials. China is currently the major waste trade partner of Hong Kong (Environmental Protection Department, 2017b). Since Hong Kong is a separate entity in trading affairs under the constitutional principle "One country, two systems", values of exported recyclables fluctuate according to global prices (Kao, 2016). The unstable price risks profit of traders and cause fluctuations in local recycling activities. Under the laissez-faire economic policy, the recycling industry received insufficient financial and technical support from the government. The business environment is becoming increasingly difficult which severely retards the development of local recycling industry. The target of getting more people engaging in recycling practice can only be met by accomplishing with full-fledged recycling system. Given that the government has set the target of pushing recycling rate to 55\% by 2022 (Environment Bureau, 2013), the high level of support for capacity-building measures (PS6-PS8) is the wish of 
the people that the government should take up more responsibility to develop local recycling industry.

A considerable number of studies proved that deficiency of knowledge such as separation methods and list of appropriate materials for recycling is a barrier for engaging in recycling practices (Guidotti and Abercrombie, 2008; Mueller, 2013; Xiao et al., 2017). Successful informational strategies would increase awareness of environmental problems among people and persuasively influence individuals' behavior (Steg and Vlek, 2009). In Hong Kong, a lack of promotional work in relation to recycling knowledge may account for the less welcomed current publicity and education work provided that the city only started to launch a Clean Recycling Campaign for promoting clean recycling in 2015 (Environmental Protection Department, 2017a).

Under the framework of Producer Responsibility Scheme (PRS), manufacturers have responsibility for the environmental impacts of a product throughout its entire life cycle, with particular emphasis on recycling and recovery processes of the product (Lindhqvist, 2000; OECD, 2001). Different groups of stakeholders such as producers, retail sectors, and consumers would bear the cost of managing and recycling end-of-life products (McKerlie et al., 2006; Triguero et al., 2016). Prior studies revealed that 52.5\% of Kuala Lumpur respondents and $68.6 \%$ of Beijing residents expressed their willingness to pay for improvement of PRS management system or end-of-life product recycling (Afroz et al., 2013; Tian et al., 2016). The results are shared by this current study that around 65\% Hong Kong respondents recognized the need of extending PRS (PS4; Table 2). Nonetheless, some research found a contradictory result that respondents express their reluctance to bear the responsibility of additional cost (e.g., Islam et al., 2016; Wang et al., 2011).

Meanwhile, the Hong Kong government has not yet introduced mandatory PRS for major consumer products (e.g., vehicle tyres, packaging materials). PRS is a legal regulation which change the costs and benefits of performing behavior alternatives; a context with no structural strategies is less likely to drive people towards pro-environmental behavior (ölander and ThØgersen, 1995; Steg and Vlek, 2009). Given incomprehensive regulations and limited recycling channels, there are a large volume of excessive packaging materials and obsolete products being disposed of in landfills every day; for instance, over 300 tonnes of beverage glass and 190 tonnes of waste electrical and electronic equipment (WEEE) were disposed of in landfill every day in Hong Kong (Environmental Protection Department, 2017c; Ling et al., 2013). The support for extending PRS to other recyclables implies that respondents consider both consumers and producers should have a role to play in reducing environmental impacts of consumer products.

Studies of pay-as-you-throw (PAYT) systems revealed that considerable number of people oppose against any types of waste charging schemes (e.g., Brown and Johnstone, 2014; Challcharoenwattana and Pharino, 2016; Xiao et al., 2017). Echoed with these studies, Hong Kong people do not consider Municipal Solid Waste Charging Scheme as a preferable option. The least supportive of the scheme may partially due to inadequate provision of source separation facilities throughout the territory. Since the objective of waste charging scheme is creating economic incentive for people to separate and recycle waste, sufficient ancillary facilities should be provided to recyclers in order to absorb the increased flow of source- 
separated materials. As Puig-Ventosa (2008) and Dunne et al. (2008) suggested, acceptability problem of charging schemes can be prevented by providing people with a great variety of recycling options which enabling them to do different types of separation. Guerrero et al. (2013) proved that stakeholders' willingness to pay for waste processing services is significantly associated with provision of recycling equipment and infrastructure by the government. Recycling facilities and waste charging scheme supplement and complement each other. Given that the MSW charging scheme is scheduled to launch in 2019 (Information Services Department, 2017), the Hong Kong government is advised to increase recycling facilities and infrastructure for making the implementation of the charging scheme more feasible in the future.

\subsection{The influence of socio-demographic characteristics on policy support}

Gender emerged as a strong predictor of policy support (Table 3). Conventional wisdom holds that females usually exhibit more concerned about environmental issues than their male counterparts (Gifford and Sussman, 2012; Hunter et al., 2004; Jones and Dunlap, 1992; Stern et al., 1993; Zelezny et al., 2000). Female respondents in this study demonstrated a similar pattern. Echoed with studies by Bartelings and Sterner (1999), Challcharoenwattana and Pharino (2016), Klineberg et al. (1998), and Triguero et al. (2016), the pattern indicates that women compared with men are more willing to support government spending or accept higher costs to accomplish environmental protection. The pro-environmental inclination and hence the increased likelihood of support for waste management policy may attribute to women's perceived vulnerability to risk and perceived role as caregivers (Bord and O'Connor, 1997), and their greater interest in health issues (Davidson and Freudenburg, 1996; Dietz et al., 2002). The findings also support for the study by Triguero et al. (2016) that women are more willing to bear greater environmental responsibility and take environmental issues as part of personal responsibility than men.

Prior research and empirical evidence suggested that age is a powerful predictor of environmental concern (exception see Ferrara \& Missios, 2005 and Triguero et al., 2016), with younger generation tends to involve in pro-environmental behaviors or support for environmental policies than older population (Brown and Johnstone, 2014; Carman, 1998; Dietz et al., 1998; Gelissen, 2007; Jones and Dunlap, 1992; Sidique et al., 2010b; Van Liere and Dunlap, 1980). It is suggested that young generation has more opportunities of receiving education and thus increase the understanding of environmental problems; hence, they tend to act in favor of the environment or to be more acceptance of environmental policies. However, this study presented a different view that a lower level of support for certain waste management policies is associated with younger generation, a result further provides empirical evidence to studies conducted by Samdahl and Robertson (1989) and Shen and Saijo (2008). The youngest age group 18-29 compared with their mature counterparts is less supportive of both charging schemes (PS2 \& PS3; Table 4) and instruments in developing local recycling industry (PS7 \& PS8; Table 4). An emerged cohort pattern different from results of previous studies may be explained by a general declining confidence in institutions among young people (Smith, 2005). The younger generation in Hong Kong has been a core participant of major chaotic events and social movements in recent years (Lau, 2014), and their skeptical of government's administrative and political capability and opposite against public policies may affect their perception of environmental policies. 
Hong Kong respondents with low education level are prone to support for enhancing publicity and education campaigns on waste reduction (Table 5), a result which is consistent with findings by Samdahl and Robertson (1989). This is probably because lower educated people have fewer opportunities to receive knowledge about environmental issues and they may assume government's responsibility but not their responsibility to protect the environment (Triguero et al., 2016). Another noteworthy result is that people with Bachelor's degree compared with their Master's degree or above counterparts are significantly less support for the establishment of Recycling Fund (PS6) and investment in recycling infrastructure (PS8). The statistical results of these two policy items are consistent with findings of most previous studies such as Gelissen (2007), Jones and Dunlap (1992), and Shen and Saijo (2008). The findings also support the argument that higher-educated people are more aware of environmental issues and able to identify root cause of the problems (Van Liere and Dunlap, 1980).

Regarding the income effect (Table 6), though statistical result revealed a similar finding with previous research (e.g., Elliott et al., 1995; Gelissen, 2007) that it is positively correlated to level of policy support (Pillai's trace $=0.140 ; p=0.027$ ), it has no significant effect across different waste management policies. A possible explanation is that most assessed policy options have no direct cost imposed on respondents, and those strategies may only be short-lived interventions (see Abrahamse et al., 2005). For example, the charging fee was only made at $\mathrm{HK} \$ 0.5$ per bag under the current Plastic Shopping Bag Levey; meanwhile, the Municipal Solid Waste Charging is a proposed scheme which has yet been finalized and introduced.

Typically, household size is negatively associated with the support for unit-based municipal waste charging scheme. This is because a large family would assume greater financial burden when the charging mode is set as variable rate (e.g., weight-based or head-counted). Triguero et al. (2016) proved the argument that respondents from larger size of family are less willing to bear consumer-based waste management options. However, the present study highlighted that the change of household size has no significant difference in level of support for Municipal Solid Waste Charging Scheme (Table 7), the result echoed with study by Afroz et al. (2009) and Brown and Johnstone (2014). It may due to the fact that the government has yet finalized charging method of the scheme at the time the interview was conducted. Moreover, other factors such as the quality of waste management services may confound the relationship between household size and willingness to pay for the scheme or services (see also Afroz et al., 2009; Guerrero et al., 2013).

Political affiliation is a frequently used variable for testing the level of support for environmental issues (Liu et al., 2014). Liberal respondents usually show greater willingness to environmental protection; whereas their counterparts, conservatives, prefer market solutions for environmental problems and thus tend to disagree with too much government intervention (Jones and Dunlap, 1992; Konisky et al., 2008; McCright et al., 2014; Samdahl and Robertson, 1989; Wood and Vedlitz, 2007). Regarding the case of Hong Kong, even though pro-localism camp respondents distinguished themselves from other political-affiliated respondents by showing a lower level of support for Plastic Shopping Bag Levy and publicity work on waste reduction, other political-affiliated respondents indicated a similar degree of agreement across waste management policies (Table 8). The trend lies in the facts that environmental affairs in Hong Kong are nonpartisan issues, resulting in people with different political affiliation share a similar 
view on environmental protection. Besides, the negative association with pro-localism camp respondents may be their extension of discontent with the government's overall performance.

\subsection{Toward a coherent and widely-supported waste management}

Preceding subsection revealed that the administration intends to reduce landfilling reliance by introducing a series of policy tools in the hope of encouraging more recycling behaviors and minimizing waste. Yet there is a lack of corresponding measures work with current policies in developing the waste management framework at a more complementary level. As Wilson (1996) has pointed out, no policy tool on its own can effectively actualize the goal of sustainable waste management. The piecemeal-style framework would likely result in fragmented policies that fail to gain public support and become ineffective for waste problems. To reach an effective and widely-supported sustainable waste management, our study highlights the importance of driving the current framework toward a more coherent and systematic model by changing the magnitude and nature of existing policies while initiating complementary measures whereas necessary. Figure 1 depicts the logic of optimal combination of policy framework based on the findings. The variety of waste policies can be grouped under the category of information dissemination, economic incentive, facilitation, and regulation according to their nature. A coherent framework suggests that each policy category should not come in isolation. Rather, it is interrelated which the implementation of one type of policy is coupled with corresponding measures for mutual reinforcement. It is only under such a complementary structure and the interplay between different policy categories that policy implementation can achieve an optimal effect and secure a broader public support.

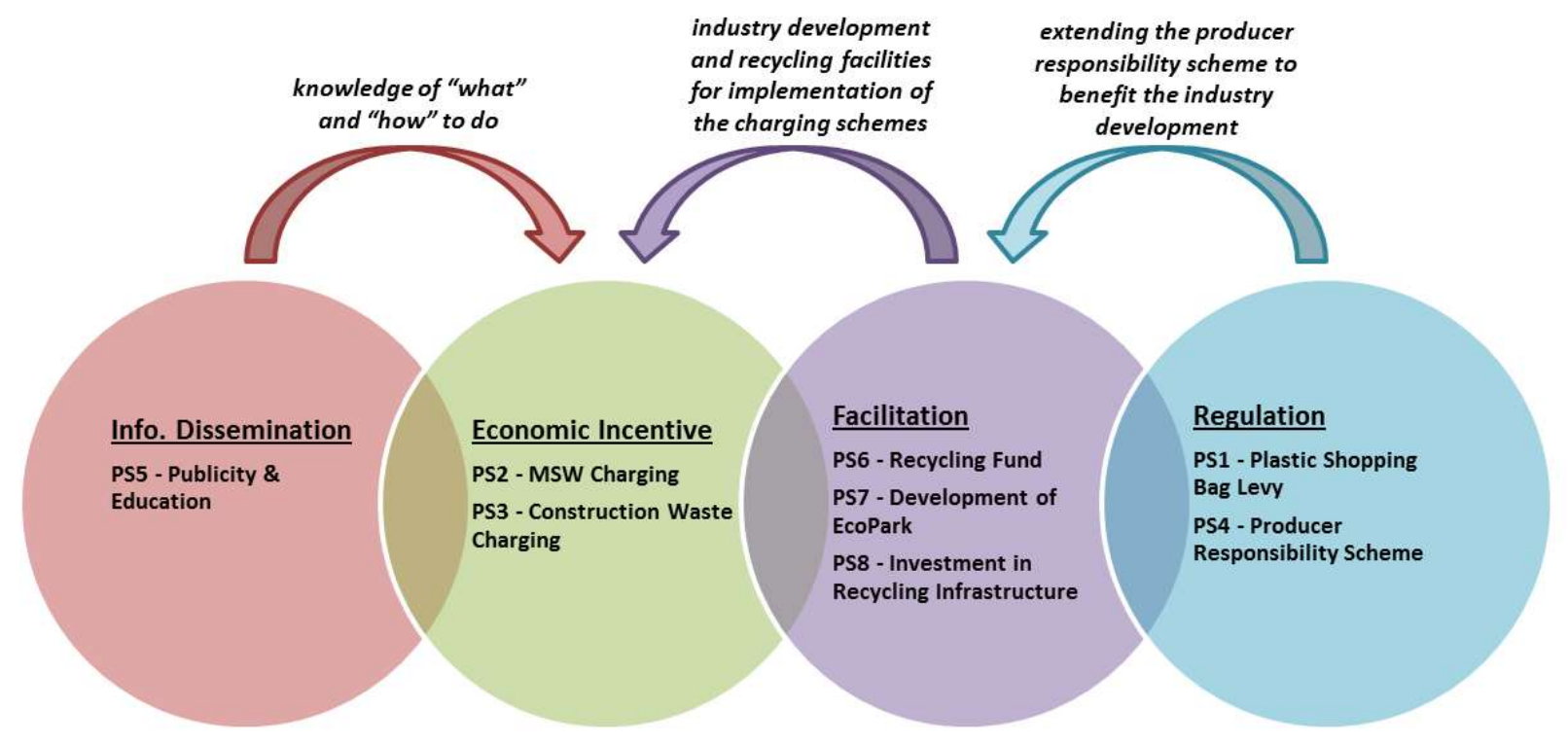

Figure 1. A coherent waste management framework

Provision of recycling facilities, infrastructure, and institutional support lays solid building blocks of effective sustainable waste management. Balch (1980) labeled this set of measures as facilitation which seeks to create an environment facilitating recycling development through the means of providing monetary support, subsidies, land resources, facilities, infrastructure, 
institutions or service to both the public and private sectors. The availability of recycling chain for waste separation, collection, and recovery makes recycling as a practicable behavior (Guerrero et al., 2013). It serves as a means of complementing the implementation of economic incentive measure such as waste charging scheme (Figure 1). Waste charging drives people participating more in recycling activities. The quantity of separated waste is mostly associated with the introduction of economic incentive measures. Thus, there should be a well-developed recycling chain for processing the increased volume of collected recyclables. Policy-makers are advised to devote considerable effort in developing measures of facilitation if sustainable development is taken as a waste management strategy.

Comprehensive regulation provides a legal framework for the implementation of sustainable waste management (Manaf et al., 2009). Regulation is laws and statutes that legally restrict one's behaviors and require compliant behaviors under threat of punishment (Balch, 1980; Vedung, 1998). Our study showed that an immature regulation for the Producer Responsibility Scheme (PRS) is not conducive to promotion of recycling behavior. With imperfect regulation, consumers cannot avoid over-packaging materials and have limited channels for recovery of endof-life products. The recyclables can only end up at landfills which the practice is contradictory to sustainable waste management. The high level of support for expanding the PRS revealed in our findings denotes an urgency to accelerate the regulation and the need to comprehend recycling regulations. Enhancing the legislation of PRS to a wider coverage of consumer products and packaging materials helps shift the cost of taxpayers to producers and consumers, with a view to embody "polluter-pays" principle. On the other hand, comprehensive recycling regulations guarantees a stable supply of recyclables for recycling industry, which in turn, benefits the development of the whole recycling chain and facilitate waste separation behavior among the public.

Every waste management policy needs to be supported by promotional campaigns (Wilson, 1996), particularly for the policies that require individuals to change their behaviors, such as waste charging scheme. Policy instruments based on information dissemination mainly refer to publicity and education programs spreading information about existence and meaning of a policy, and action required to be taken to achieve policy goals (Balch, 1980; Vedung, 1998; Wilson, 1996). It has all along been regarded as an effective measure to increase recycling participation as instructions and guidelines help reduce the cost of recycling behaviors (Mueller, 2013; Sidique et al., 2010a). Traditional education campaigns aim at increasing recycling awareness and encouraging participation (Xiao et al., 2017). Nonetheless, the less-supported publicity measures found in our study may imply that content of information dissemination should be designed in accordance with the actual circumstance. For instance, policy-makers may highlight message "how to do" rather than only stick to programs about "what to do" when introducing policies that aim at changing individual behaviors.

Economic incentive policies work by offering positive or negative financial incentive that guide individuals' behaviors toward the desired ends of policy (Schneider and Ingram, 1990; Wilson, 1996). Though it provides incentive for people to minimize waste and increase recycling practices and its positive effect on recycling behaviors has been confirmed (Ferrara and Missios, 2005; Yang and Innes, 2007), the success of its implementation relies heavily on the accompany of other types of policy tools as illustrated in Figure 1. Take Hong Kong case as an example, the 
soon introduced MSW waste charging scheme is likely to result in an increase of recycling practices and quantity of recyclables. In view of this, education programs provide people with all necessary information, as well as recycling facilities and recovery infrastructure should be prepared to take up possible challenges derived from economic incentive measures.

In view of driving toward sustainable waste management, a key policy recommendation for Hong Kong is that policies of facilitation should receive priority attention. The inadequate recycling facilities, infrastructure, and institutional support hamper the development of recycling industry and hinder the implementation of sustainable waste management strategies in Hong Kong. The majority of the respondents (65\%) agreed with government's investment in recycling infrastructure. On the one hand, the number of recycling bins and scope of recyclables recovered should be increased and extended to facilitate recycling practices among the public while the number of rubbish bin needs to be slashed for the preparation of PRS extension and the introduction of MSW charging scheme; on the other hand, the administration should also take a proactive role to develop a comprehensive recycling chain as a response to such a high level of support for infrastructure investment (PS8) and development of recycling industry (PS6, PS7). Setting up a resource recycling center for collecting and processing separated waste in every district would be an option. The community-based center not only facilitates individuals' recycling behavior, but also ensures a steady supply of recyclables from the community. Shortage of land for storing separated waste and low profit return discourage the development of recycling industry in Hong Kong. In addition to Recycling Fund and EcoPark, the government is called for providing the industry with comprehensive financial support and more rentable land under long-term tenancies, as well as offering up-to-date recycling technology in order to reduce the operational cost of recycling business.

This study found that respondents have a high level of support for extending Producer Responsibility Scheme to other consumer products such as packaging materials and tyres. In view of this, the government is suggested to expedite the enactment of legislation to provide a legal basis for sustainable waste management. The extended scheme also provides a stable source of recyclables supply for local recycling industry.

Our results revealed that public is less satisfied with current education and publicity work for waste reduction. In view of this, we suggest a shift of education theme from "what to do" to "how to do." Instead of encouraging the participation of recycling, proper recycling practices should become the core theme of future publicity work and education campaigns. The change would equip the citizens with proper recycling knowledge and prepare them for the implementation of charging scheme while clean and sorted waste adds value to the recyclables.

\subsection{Socio-demographic factors, public support, and intervention strategies}

Several socio-demographic factors were found to be significant in the variation of policy support for certain policies. Though it may be difficult to manipulate socio-demographic characteristics such as gender, age, and education level, it is still possible for the government to recruit public support by providing tailored information, making use of different information-spreading channels, and introducing an inclusive decision process. 
To encourage behavior change of different social groups, tailored information is proved to be more effective compared with unified messages for the entire population (Abrahamse and Matthies, 2012). In our study, males, young people aged 18-29 and higher educated respondents possess less support for waste policies. Customized information meeting the recipients' background and relating to behavioral outcomes becomes increasingly important. Behaviour are more likely to change if messages have taken recipients' background and situation into account (Abrahamse et al., 2007). For example, it might be more effective to design information specific for males by stressing the point that showing support for waste policies aims at providing a clean living environment for their family and future generation.

The present study noticed that variation of support for certain policies exist among young generation and respondents with higher education. The novel and vibrant perspective of these groups of population deserves more efforts for collecting their opinion. Technology may help in this case. New social network such as Facebook and Twitter nowadays overtakes the traditional media like television as a major channel for spreading information. Fast in speed and instant feedback contribute to the popular use of networks among these groups of population. Policymakers may take advantage of new forms of social network to reach a broader public.

Public participation has been increasingly recognized as a crucial element in waste management decision-making processes (Sharholy et al., 2008; Wan et al., 2017). It enhances public understanding of proposed initiatives (Guerrero et al., 2013) and offers opportunities for different population segments for exchanging their opinions with policy-makers, which in turn, help formulate a more representative policy. The integration of a broad range of opinions from the public with diversified backgrounds heightens the level of public support for waste management policies. The practice can also restore the confidence of the public, especially young people, in government's administrative capacity, as it is a concrete expression of government's determination and commitment to solve waste problems.

\section{Conclusion}

This study found that differential support for policy exists across different instruments in Hong Kong, with recycling infrastructure and extension of PRS are most welcomed by the majority of respondents while MSW charging scheme is least supported. Confined with prior studies, gender, age, and education level significantly associate with policy support across waste management options. Investigation suggests that uncoordinated and fragmented waste management framework account for the ineffectiveness of measures and, in turn, the patterns of policy support. In view of this, a coherent and complementary waste management framework is constructed based on the results and discussion. Different from other proposed frameworks which emphasize the hierarchy and priority of waste policy (e.g., Triguero et al., 2016; Xiao et al., 2017), this framework brings attention to the complementary nature of different policy categories and highlights the mechanism of mutual reinforcement between policies. The findings provide policy-makers with evidence for waste management policy formulation and implementation. The research contributes to current literature of waste management in cities which share similar background with Hong Kong. The demographic differences across policy instruments and proposed coherent waste management framework add valuable reference to existing literature. 
The present study is also relevant in waste management discussion of many other cities as findings are based on analysis of a broad range of common waste management policy.

Page 22 of 27 


\section{References}

Abrahamse, W., Matthies, E., 2012. Information strategies to promote pro-environmental behaviour: Changing knowledge, awareness and attitudes, in: Steg, L., van den Berg, A.E., de Groot, J.I.M. (Eds.), Environmental Psychology: An Introduction. Wiley-Blackwell, Chichester [England]; Malden, Mass.

Abrahamse, W., Steg, L., Vlek, C., Rothengatter, T., 2005. A review of intervention studies aimed at household energy conservation. Journal of Environmental Psychology 25(3), 273-291.

Abrahamse, W., Steg, L., Vlek, C., Rothengatter, T., 2007. The effect of tailored information, goal setting, and tailored feedback on household energy use, energy-related behaviors, and behavioral antecedents. Journal of Environmental Psychology 27, 265-276.

Afroz, R., Hanaki, K., Hasegawa-Kurisu, K., 2009. Willingness to pay for waste management improvement in Dhaka city, Bangladesh. Journal of Environmental Management 90, 492-503.

Afroz, R., Masud, M.M., 2011. Using a contingent valuation approach for improved solid waste management facility: Evidence from Kuala Lumpur, Malaysia. Waste Management 31(4), 800808.

Afroz, R., Masud, M.M., Akhtar, R., Duasa, J.B., 2013. Survey and analysis of public knowledge, awareness and willingness to pay in Kuala Lumpur, Malaysia - a case study on household WEEE management. Journal of Cleaner Production 52, 185-193.

Ariola, M.M., 2006. Principles and Methods of Research. Rex Book Store, Inc., Manila, Phillipines.

Audit Commission, 2015. Director of Audit's Report No. 65. Hong Kong Audit Commission, Hong Kong.

Balch, G.I., 1980. The stick, the carrot, and other strategies: A theoretical analysis of governmental intervention. Law \& Policy Quarterly 2(1), 35-60.

Barr, S., Gilg, A., Ford, N., 2005. Defining the multi-dimensional aspects of household waste management: A study of reported behavior in Devon. Resources, Conservation and Recycling 45(2), 172-192.

Bartelings, H., Sterner, T., 1999. Household waste management in a Swedish municipality: Determinants of waste disposal, recycling and composting. Environmental and Resource Economics 13(4), 473491.

Blocker, T.J., Eckberg, D.L., 1989. Environmental Issues as Women's Issues: General Concerns and Local Hazards. Social Science Quarterly 70, 586-593.

Bord, R.J., O'Connor, R.E., 1997. The Gender Gap in Environmental Attitudes: The Case of Perceived Vulnerability to Risk. Social Science Quarterly 78(4), 830-840.

Brown, Z.S., Johnstone, N., 2014. Better the devil you throw: Experience and support for pay-as-youthrow waste charges. Environmental Science \& Policy 38, 132-142.

Carman, C.J., 1998. Dimensions of Environmental Policy Support in the United States. Social Science Quarterly 79(4), 717-733.

Census and Statistics Department, 2016. Thematic Household Survey Report - Report No. 59, in: Department, C.a.S. (Ed.). The Government of Hong Kong Special Administrative Region, Hong Kong.

Challcharoenwattana, A., Pharino, C., 2016. Wishing to finance a recycling program? Willingness-to-pay study for enhancing municipal solid waste recycling in urban settlements in Thailand. Habitat International 51, 23-30.

Convery, F., McDonnell, S., Ferreira, S., 2007. The most popular tax in Europe? Lessons from the Irish plastic bags levy. Environmental and Resource Economics 38, 1-11.

Davidson, D.J., Freudenburg, W.R., 1996. Gender and environmental risk concerns: A review and analysis of available research. Environment and Behavior 28(3), 302-339.

Dietz, T., Kalof, L., Stern, P.C., 2002. Gender, values, and environmentalism. Social Science Quarterly 83(1), 353-364.

Dietz, T., Stern, P.C., Guagnano, G.A., 1998. Social structural and social psychological bases of environmental concern. Environment and Behavior 30(4), 450-471.

Page 23 of 27 
Dunne, L., Convery, F.J., Gallagher, L., 2008. An investigation into waste charges in Ireland, with emphasis on public acceptability. Waste Management 28(12), 2826-2834.

Elliott, E., Regens, J.L., Seldon, B.J., 1995. Exploring Variation in Public Support for Environmental Protection. Social Science Quarterly 76(1), 41-52.

Environment Bureau, 2013. Hong Kong Blueprint for Sustainable Use of Resources 2013-2022. Hong Kong Environment Bureau, Hong Kong.

Environmental Protection Department, 2017a. Hong Kong Fact Sheet. http://www.epd.gov.hk/epd/english/about epd/hk fact_sheet.html. (Accessed 11 September 2017).

Environmental Protection Department, 2017b. Monitoring of Solid Waste in Hong Kong 2015. Hong Kong Environmental Protection Department, Hong Kong.

Environmental Protection Department, 2017c. Producer Responsibility Schemes. http://www.epd.gov.hk/epd/english/environmentinhk/waste/pro responsibility/index.html. (Accessed 20 May 2017).

Ferrara, I., Missios, P., 2005. Recycling and Waste Diversion Effectiveness: Evidence from Canada. Environmental and Resources Economics 30(2), 221-238.

Fowler, F.J., 2014. Survey Research Methods. SAGE, Los Angeles.

Gelissen, J., 2007. Explaining popular support for environmental protection a multilevel analysis of 50 nations. Environment and Behavior 39(3), 392-415.

George, D., Mallery, P., 2016. IBM SPSS statistics 23 step by step: a simple guide and reference. Routledge, New York.

Gifford, R., Sussman, R., 2012. Environmental Attitudes, in: Clayton, S.D. (Ed.) The Oxford Handbook of Environmental and Conservation Psychology. Oxford University Press, New York, United States, pp. 65-80.

Guerrero, L.A., Maas, G., Hogland, W., 2013. Solid waste management challenges for cities in developing countries. Waste Management 33(1), 220-232.

Guidotti, T.L., Abercrombie, S., 2008. Aurum: a case study in the politics of NIMBY. Waste Management \& Research 26(6), 582-588.

Hine, D.W., Kormos, C., Marks, A.D.G., 2016. Agree to Disagree A Practical Guide to Conducting Survey Research in Environmental Psychology, in: Gifford, R. (Ed.) Research Methods for Environmental Psychology. Wiley, Hoboken, pp. 71-91.

Hunter, L.M., Hatch, A., Johnson, A., 2004. Cross-national gender variation in environmental behaviors. Social Science Quarterly 85, 677-694.

Information Services Department, 2015. Hong Kong Yearbook. Hong Kong Information Services Department, Hong Kong.

Information Services Department, 2017. Implementation arrangements for municipal solid waste charging (with photo). http://www.info.gov.hk/gia/general/201703/20/P2017032000453.htm?fontSize=1. (Accessed 15 May 2017).

Islam, M.T., Abdullah, A.B., Shahir, S.A., Kalam, M.A., Masjuki, H.H., Shumon, R., Rashid, M.H., 2016. A public survey on knowledge, awareness, attitude and willingness to pay for WEEE management: Case study in Bangladesh. Journal of Cleaner Production 137, 728-740.

Jones, R.E., Dunlap, R.E., 1992. The social bases of environmental concern: Have they changed over time? Rural Sociology 57(1), 28-47.

Kao, E., 2014. Huge number of rubbish bins in Hong Kong is contributing to waste crisis, says activist, South China Morning Post. South China Morning Post, Hong Kong.

Kao, E., 2016. Hong Kong government lashed over 'cumbersome' procedures for seeking recycling fund money, South China Morning Post. South China Morning Post, Hong Kong.

Klineberg, S.L., McKeever, M., Rothenbach, B., 1998. Demographic predictors of environmental concern: It does make a difference how it's measured. Social Science Quarterly 79(4), 734-753.

Ko, P.S., Poon, C.S., 2009. Domestic waste management and recovery in Hong Kong. Journal of Material Cycles and Waste Management 11(2), 104-109. 
Kollmuss, A., Agyeman, J., 2002. Mind the gap: why do people act environmentally and what are the barriers to pro-environmental behavior? Environmental Education Research 8(3), 239-260.

Konisky, D.M., Milyo, J., Richardson, L.E., 2008. Environmental Policy Attitudes: Issues, Geographical Scale, and Political Trust. Social Science Quarterly 89(5), 1066-1085.

Ladd, A.E., 1990. The Solid Waste Crisis and Support for Recycling: A Research Note. Sociological Spectrum 10, 469-484.

Lau, C.H.M., 2014. Political Participation of the Post-80s Generation - Their Protest Activities and Social Movements in Recent Years in Hong Kong, in: Cheng, J.Y.S. (Ed.) New Trends of Political Participation in Hong Kong. City University of Hong Kong Press, Hong Kong, pp. 385-415.

Lindhqvist, T., 2000. Extended Producer Responsibility in Cleaner Production: Policy Principle to Promote Environmental Improvements of Product Systems, The International Institute for Industrial Environmental Economics. Lund University, Scania, Sweden.

Ling, T.-C., Poon, C.-S., Wong, H.-W., 2013. Management and recycling of waste glass in concrete products: Current situations in Hong Kong. Resources, Conservation and Recycling 70, 25-31.

Liu, X., Vedlitz, A., Shi, L., 2014. Examining the determinants of public environmental concern: Evidence from national public surveys. Environmental Science \& Policy 39, 77-94.

Manaf, L.A., Samah, M.A.A., Zukki, N.I.M., 2009. Municipal solid waste management in Malaysia: Practices and challenges. Waste Management 29(11), 2902-2906.

McCright, A.M., Xiao, C., Dunlap, R.E., 2014. Political polarization on support for government spending on environmental protection in the USA, 1974-2012. Social Science Research 48, 251-260.

McKerlie, K., Knight, N., Thorpe, B., 2006. Advancing Extended Producer Responsibility in Canada. Journal of Cleaner Production 14, 616-628.

Milovantseva, N., 2016. Are American households willing to pay a premium for greening consumption of Information and Communication Technologies? Journal of Cleaner Production 127, 282-288.

Mueller, W., 2013. The effectiveness of recycling policy options: Waste diversion or just diversions? Waste Management 33, 508-518.

OECD, 2001. Extended Producer Responsibility: a Guidance Manual for Governments. OECD, Paris, France.

ölander, F., ThØgersen, J., 1995. Understanding of consumer behaviour as a prerequisite for environmental protection. Journal of Consumer Policy 18(4), 345-385.

Oskamp, S., 1995. Resource conservation and recycling: Behavior and policy. Journal of Social Issues 51(4), 157-173.

Puig-Ventosa, I., 2008. Charging systems and PAYT experiences for waste management in Spain. Waste Management 28(12), 2767-2771.

Rauwald, K.S., Moore, C.F., 2002. Environmental attitudes as predictors of policy support across three countries. Environment and Behavior 34(6), 709-739.

Ryan, T.P., 2013. Sample size determination and power. Wiley, New York.

Samdahl, D.M., Robertson, R., 1989. Social determinants of environmental concern specification and test of the model. Environment and Behavior 21(1), 57-81.

Saphores, J.-D.M., Nixon, H., Ogunseitan, O.A., Shapiro, A.A., 2006. Household Willingness to Recycle Electronic Waste An Application to California. Environment and Behavior 38(2), 183-208.

Schneider, A., Ingram, H., 1990. Behavioral Assumptions of Policy Tools. Journal of Politics 52(2), 510529.

Schultz, P.W., Oskamp, S., Mainieri, T., 1995. Who recycles and when? A review of personal and situational factors. Journal of Environmental Psychology 15, 105-121.

Scott, D., 1999. Equal opportunity, unequal results: Determinants of household recycling intensity. Environment and Behavior 31, 267-290.

Sharholy, M., Ahmad, K., Mahmood, G., Trivedi, R.C., 2008. Municipal solid waste management in Indian cities -A Review. Waste Management 28(2), 459-467. 
Shen, J., Saijo, T., 2008. Reexamining the relations between socio-demographic characteristics and individual environmental concern: Evidence from Shanghai data. Journal of Environmental Psychology 28, 42-50.

Sidique, S.F., Joshi, S.V., Lupi, F., 2010a. Factors influencing the rate of recycling: An analysis of Minnesota counties. Resources, Conservation and Recycling 54(4), 242-249.

Sidique, S.F., Lupi, F., Joshi, S.V., 2010b. The effects of behavior and attitudes on drop-off recycling activities. Resources, Conservation and Recycling 54, 163-170.

Smith, T.W., 2005. Generation Gaps in Attitudes and Values from teh 1970s to teh 1990s, in: Settersten, R.A., Furstenberg, F.F., Rumbaut, R.G. (Eds.), On the Frontier of Adulthood: Theory, Research, and Public Policy. University of Chicago Press, Chicago, pp. 177-221.

Steg, L., Vlek, C., 2009. Encouraging pro-environmental behaviour: An integrative review and research agenda. Journal of Environmental Psychology 29, 309-317.

Stern, P.C., 2000. New Environmental Theories: Toward a Coherent Theory of Environmentally Significant Behavior. Journal of Social Issues 56(3), 407-424.

Stern, P.C., Dietz, T., Abel, T.D., Guagnano, G.A., Kalof, L., 1999. A value-belief-norm theory of support for social movements: The case of environmentalism. Human Ecology Review 6(2), 8197.

Stern, P.C., Dietz, T., Kalof, L., 1993. Value orientations, gender, and environmental concern. Environment and Behavior 25(5), 322-348.

Tian, X., Wu, Y., Qu, S., Liang, S., Xu, M., Zuo, T., 2016. The disposal and willingness to pay for residents' scrap fluorescent lamps in China: A case study of Beijing. Resources, Conservation and Recycling 114, 103-111.

Triguero, A., Álvarez-Aledo, C., Cuerva, M., 2016. Factors influencing willingness to accept different waste management policies: empirical evidence from the European Union. Journal of Cleaner Production 138, 38-46.

Van Liere, K.D., Dunlap, R.E., 1980. The social bases of environmental concern: A review of hypotheses, explanations and empirical evidence. Public Opinion Quarterly 44(2), 181-197.

Vedung, E., 1998. Policy instruments: typologies and theories, in: Bemelmans-Videc, M.-L., Rist, R.C., Vedung, E. (Eds.), Carrots, Sticks, and Sermons: Policy Instruments and Their Evalution. Transaction Publishers, New Brunswick; London.

Wan, C., Shen, G.Q., Choi, S., 2017. A review on political factors influencing public support for urban environmental policy. Environmental Science \& Policy 75, 70-80.

Wan, C., Shen, G.Q., Yu, A., 2015. Key determinants of willingness to support policy measures on recycling: A case study in Hong Kong. Environmental Science \& Policy 54, 409-418.

Wang, Z., Zhang, B., Yin, J., Zhang, X., 2011. Willingness and behavior towards e-waste recycling for residents in Beijing city, China. Journal of Cleaner Production 19, 977-984.

Wilson, D.C., 1996. Stick or Carrot?: The Use Of Policy Measures To Move Waste Management Up The Hierarchy. Waste Management \& Research 14, 385-398.

Wood, D.B., Vedlitz, A., 2007. Definition, Information Processing, the Politics and of Global Warming. American Journal of Political Science 51(3), 552-568.

Woodring, D., 2015. Hong Kong's woeful recycling efforts a result of mistrust in the system and lack of government support for the industry, South China Morning Post. South China Morning Post, Hong Kong.

Xiao, L., Zhang, G., Zhu, Y., Lin, T., 2017. Promoting public participation in household waste management: A survey based method and case study in Xiamen city, China. Journal of Cleaner Production 144, 313-322.

Yang, H.-L., Innes, R., 2007. Economic Incentives and Residential Waste Management in Taiwan: An Empirical Investigation. Environmental and Resources Economics 37(3), 489-519.

Zelezny, L.C., Chua, P.-P., Aldrich, C., 2000. Elaborating on Gender Differences in Environmentalsim. Journal of Social Issues 56(3), 443-457. 
Zeng, C., Niu, D., Li, H., Zhou, T., Zhao, Y., 2016. Public perceptions and economic values of sourceseparated collection of rural solid waste: A pilot study in Chin. Resources, Conservation and Recycling 107, 166-173. 